\title{
Synthesis of Green Metallic Nanoparticles (NPs) and Applications
}

\author{
VARAHALARAO VADLAPUDI ${ }^{*}$, D.S.V.G.K.KALADHAR ${ }^{2}$, \\ MOHAN BEHARA $^{3}$, B.SUJATHA ${ }^{4}$ and G. KISHORE NAIDU ${ }^{4}$
}

\author{
'Department of Biochemistry, Dr Lankapalli Bullayya P G College (Affiliated to Andhra university), \\ Visakhapatnam - 530 013, India. \\ ${ }^{2}$ Department of Bioinformatics, GIS, GITAM University, Visakhapatnam - 530 045, India. \\ ${ }^{3}$ Department of Botany, P.V.K.N. Government College, Chittoor - 517 002, India. \\ ${ }^{4}$ Department of Botany, Andhra University, Vishakhapatnam - 530 003, India. \\ ${ }^{*}$ Corresponding author E-mail: vvraophd@gmail.com
}

http://dx.doi.org/10.13005/ojc/290442

(Received: October 24, 2013; Accepted: December 14, 2013)

\begin{abstract}
Nanotechnology (NT) is a field that is mushrooming, making an impact in all spheres of human life. Presently available literature revealed that the NP synthesis using medicinal plants, microorganisms and algae and others as source has been unexplored and underexploited. NT is very important in developing sustainable technologies for the future, for humanity and the environment. The development of green processes for the synthesis of NP is evolving into an important branch of nanotechnology. Natural sources of nanoparticles include fires and volcanic eruptions. The nanotechnology have short to long term uses like environmental pollution cleanup, efficient and safe drug delivery mechanisms with less side effects, developments in information technology, selfcleaning window glass, 'smart' fabrics which adjust to suit the temperature. Plant mediated synthesis of metal nanoparticles is gaining more importance owing to its simplicity, rapid rate of synthesis of NP of attractive and diverse morphologies and elimination of elaborate maintenance of cell cultures and ecofriendliness. It has many advantages such as, ease with which the process can be measured up, economic viability and etc. Presently, the researchers are looking into the development of costeffective procedures for producing reproducible, stable and biocompatible metal NPs.
\end{abstract}

Key words: Nanotechnology, Nanoparticles, Biocompatible.

\section{INTRODUCTION}

The word "nano" is used to indicate one billionth of a meter or $10-9$. Nanoparticles are clusters of atoms and their size from 1-100 nm. "Nano" is a Greek word meaning extremely small.
Nanotechnology is a field that is vast in making an impact in all fields of human life. Nano-biotechnology can be used as alternative for chemical and physical methods of nanoparticles synthesis. Nano science and nanotechnology began in late 1959 with a talk entitled "There's Plenty of Room at the Bottom" by 
physicist Richard Feynman at an American Physical Society conference, held at the Cal Tech. The term Nanotechnology (NT) was coined by Professor Norio Taniguchi of Tokyo Science University in the year 1974. Nanoparticles (NP) attract greater attention due to their various applications in different fields including "nanomedicine". NPs can be broadly grouped into two, namely, organic nanoparticles which include carbon NPs where as some of the inorganic nanoparticles include magnetic NPs, noble metal NP (like gold and silver) and semi-conductor nanoparticles (like titanium oxide and zinc oxide). Metallic nanoparticles are most promising and remarkable biomedical agents. Silver, Aluminum, Gold, Zinc, Carbon, Titanium, Palladium, Iron and Copper have been routinely used for the synthesis of NPs. Metal nanoparticles are of use in various catalytic applications, electronics, biology and biomedical applications, material science, physics, environmental remediation fields ${ }^{1-8}$. In modern Nanoscience and nanotechnology the production of nanomaterials with the preferred quality is one of the most stimulating aspects. Materials at the nanometer dimension are not new. NPs are common in nature, for example, life depends on many nanoscaled objects, including proteins, enzymes and DNA, and nanosized particles occur naturally in the atmosphere. Natural sources of nanoparticles include fires and volcanic eruptions. The nanotechnology have short to long term uses like environmental pollution cleanup, efficient and safe drug delivery mechanisms with less side effects, developments in information technology, self-cleaning window glass, 'smart' fabrics which adjust to suit the temperature. Plant and plant-derived materials for biosynthesis of metal nanoparticles mechanisms of metal ions uptake and bioreduction instigated by scientists around the globe ${ }^{9-18}$.Some of these technologies have already been adopted. Scientists are looking for longer-term applications including design of additional 'smart' materials such as food packaging which changes color when the 'use by' date of its contents expires. NT is important in developing sustainable technologies for the future, for humanity and the environment. There is a growing need to develop environmentally friendly processes through green synthesis and other biological approaches.

\section{Importance of the study}

Presently available literature revealed that the metal NPs synthesis using plants, microorganisms and algae as source has been unexplored and underexploited. Resistance to antimicrobial agents by pathogenic bacteria has emerged in recent years and is a major health problem. The development of green processes for the synthesis of NP is evolving into an important branch of green nanotechnology. Plants have evolved in the presence of natural nanomaterials. However, the probability of plant exposure to nanomaterials has increased to a greater extent with the ongoing increasing production and use of engineered nano materials in a variety of instruments and goods. Plant mediated synthesis of metal NPs is gaining more importance owing to its simplicity, rapid rate of synthesis of NP of attractive and diverse morphologies and elimination of elaborate maintenance of cell cultures and ecofriendliness.

\section{Significance and synthesis of NPs particles}

They life span of metal nanoparticles and speed up the rate of synthesis in comparison to microorganism's .Depending on the origin we can distinguish three types of NPs: natural incidental and engineered. Natural NPs have existed from earth formation and still occur in the environment in volcanic dusts and mineral composites. The general procedure using plants to produce metallic nanoparticles employs the dried biomass of the plants and a metallic salt, as bioreducing agent and precursor, respectively. The medicinal and preservative properties of silver have been known for over 2,000 years. It is a rare, but naturally available, slightly harder than gold and very ductile and malleable. Utilization of nontoxic chemicals, environmentally benign solvents, and renewable materials are some of the key issues that merit important consideration in a green synthetic strategy. Nanoparticles can be synthesized using different biological materials

Green synthesis can also use other procedures to produce NPs ${ }^{43-53 . A g N P s}$ of many different shapes (spherical, rod-shaped, truncated, triangular nanoplates) were developed by various synthetic methods.

\section{Factors Affecting Biosynthesis of Nanoparticles}

Almost all properties of nanoparticles 


\begin{tabular}{|c|}
\hline 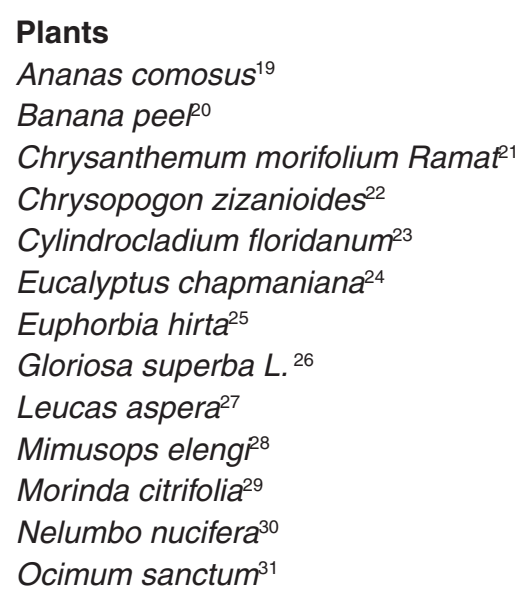 \\
\hline
\end{tabular}

are due to their small sizes. The small size of nanoparticles implies that they could get close to a biological target of interest.Synthesis of nano materials with the required quality and desired properties are one of the important issues in present greennanotechnology. Different kinds of NPs can be successfully synthesized by traditionally chemical and physical methods. The three main steps in the preparation of nanoparticles that's of green chemistry perspective are the choice of the solvent medium used for the synthesis, benign reducing agent, and nontoxic material for the stabilization of the NPs. The important in Synthesis of nano particles is the capping material used to protect its surface. Temperature plays an important role to control the aspect ratio and relative amounts of gold nanotriangles and spherical nanoparticles. $\mathrm{P}^{\mathrm{H}}$ of the medium also influences the size of nanoparticles at great concern. Other than $\mathrm{P}^{\mathrm{H}}$ and temperature other factors like concentration of extract also play role in NP synthesis and reduction process of ions into metallic nano.

For stabilization of small particles, the use of polymers, phospholipids, triblock polymers, ligands, solid matrix and surfactants has also been recommended ${ }^{54-59}$. Stabilizers are available for the stabilization of NPs in solution; these are associated with some demerits ${ }^{60}$. The preparation of nanomaterials in green solvents, such as water ${ }^{61}$ and other non-toxic solvents are now a day's very popular.

\section{Characterization of NPS}

Characterization of nanoparticles is

\author{
Phoenix dactylifera L. ${ }^{32}$ \\ Pinus eldarica ${ }^{33}$ \\ Salicornia brachiata ${ }^{34}$ \\ Sida acuta ${ }^{35}$ \\ Solanum trilobatum ${ }^{36}$ \\ Tephrosia purpurea ${ }^{37}$ \\ Tribulus terrestris ${ }^{38}$ \\ Algae \\ Sargassum muticum ${ }^{39}$ \\ Chlamydomonas reinhardtit ${ }^{40}$ \\ Fungi \\ Epicoccum nigrum ${ }^{41}$ \\ Neurospora crassa ${ }^{42}$
}

important task to understandand control over nanoparticles synthesis and applications and it can be done using developed and sophisticated techniques such as transmission and scanning electron microscopy (TEM, SEM), atomic force microscopy (AFM), dynamic light scattering (DLS), X-ray photoelectron spectroscopy (XPS), powder $X$-ray diffractometry (XRD), Fourier transform infrared spectroscopy (FTIR), and UV-Vis spectroscopy. Gold NPs ${ }^{62,63}$,Palladium (Pd) NPs are characterized by X-Ray Diffraction (XRD), UV-Vis Spectra, TEM, FTIR $^{64}$, Silver NPs used TEM, EDAX, Selected Area Diffraction Pattern (SAED) and High Resolution Transmission Electron Microscopy (HRTEM) $65,66,67$,Magnetite NPs XRD, FT-IR, SEM ${ }^{68}$,Zinc oxide (ZnO) ${ }^{69}$, Iron oxide ${ }^{70}, \mathrm{Ag}, \mathrm{Au}$ and $\mathrm{Pt}^{71}$.

\section{Separation and purification of NPS}

Capillary magnetic field flow fractionation (MFFF), HPLC, size exclusion chromatography and another important approach is centrifugation is used widely in colloid science now. Electrophoresis (GE) also can be used to separate polymer-coated spherical, rod-shaped, and triangular gold and silver nanoparticles, and Membrane ûltration.

\section{Applications}

Nanotechnology is a field that is mushrooming, making an impact in all spheres of human life. During the current scenario nanotechnology motivates progress in all sphere of life, hence biosynthetic route of nanoparticles synthesis will emerge as safer and best alternative to conventional methods. Though various biological entities have been exploited for the production of 
nanoparticles, the use of plants for the facile robust synthesis of nanoparticles is a tremendous. Toxicity of silver and other NPs are not fully understood even it is using from long time. Very recently, nanoparticles have gained significance in the field of Biomedicine. Plants and plant extracts can be effectively used in the synthesis of gold AgNPs and others as a greener route. Shape and size control of nanoparticles is easily understood with the use of plants. The nanoparticles extracted from plants are used in many applications for benefit of humans. It has applications degradation of organic pollutants ${ }^{72}$, bioremediation systems ${ }^{73}$, brain cancer ${ }^{74}$, colorimetric sensor ${ }^{75,76}$, cytotoxicity ${ }^{77}$, drug delivery 78,79 . Several researchers are designed variety of delivery vehicles based on different nanomaterials, such as polymers 80 , dendrimers 81 , liposomes ${ }^{82}$, nanotubes ${ }^{83}$ and nanorods ${ }^{84}$, antioxidant, antimicrobial and cytotoxic activities85, Targeted Fluorescence and Photoacoustic Bio-imaging ${ }^{86}$, optical enhancing and antibacterial properties ${ }^{87}$, Haemocompatibility ${ }^{88}$, biomedical applications89, theranostic applications90, Anti-metastatic ${ }^{91}$, Biogenic nanoparticles: copper, copper oxides, copper sulphides, complex copper nanostructures and their applications ${ }^{92}$, cell imaging and drug delivery ${ }^{93}$, scenario modelling ${ }^{94}$, biodiesel production $^{95}$, cancer therapy ${ }^{96}$, agriculture ${ }^{97}$, optical sensor for ammonia detection ${ }^{98}$, Catalytic degradation of organic dyes ${ }^{99}$, oxide nanosheets for enhanced catalytic applications ${ }^{100}$.The Green chemistry synthetic route can be employed for both silver and gold silver nanoparticles synthesis. Among the AgNPs, the biological organisms such as bacteria, fungi and yeast or several plant biomassor plant extracts have been used for nanoparticles synthesis used for a number of applications from electronics and catalysis to biology.

\section{CONCLUSIONS}

The "green" route for nanoparticle (Np) synthesis is of great interest due to eco-friendliness, economic prospects, and feasibility and wide range of applications in nanomedicine, new category catalysis medicine, nano-optoelectronics, etc. it is a new and emerging area of research in the scientific world, where day-by-day developments is noted in warranting a bright future for this field. this green chemistry approach toward the synthesis of $\mathrm{Ag}$, AuNps and others have many advantages such as, ease with which the process have economic viability, etc. it was concluded that biological mediated synthesis of AgNps possesses potential antimicrobial, anticoagulant activity, and anticancer activities. The characterization analysis proved that the particle so produced in nano dimensions would be equally effective as that of antibiotics and other drugs in pharmaceutical applications. The ongoing research efforts are focussed on evaluating the safety of nanomedicine and formulating the international regulatory guidelines for the same, which is critical for technology advancement. With vast technology push, there are many challenges head that need to be understood and solve in order to make the NP-based products commercially viable. Presently, the researchers are looking into the development of cost-effective procedures for producing reproducible, stable and biocompatible metallic NPs from bioresources.

\section{ACKNOWLEDGEMENTS}

I am thankful to Department of Biochemistry, Dr L Bullayya Post Graduate College, Visakhapatnam, India, GITAM University, P.V.K.N. Government College, Chittoor and Andhra University for support and constant encouragement.

\section{REFERENCES}

1. González A. L., and Noguezm C. Journal of Computational and Theoretical Nanoscience., 4: 231-238 (2007).

2. Gross M., Winnacker M. A., and Wellmann, P. J. hin Solid Films., 515: 8567-8572 (2007).

3. Kim J.Y., Kim M., Kim H.M., Joo J., and Choi J. p-tical Materials., 21: 147-151 (2003).
4. Parak W. ., Gerion D., Pellegrino T., Zanchet D., Micheel C., WilliamsS. C., BoudreauR., Le Gros M.A., Larabell C. A., and Alivisatos A. P. Nanotechnology., 14:

5. Schultz D.A. Current Opinion Biotech., 14: 13-22 (2003).

6. Smith M., Duan H., Rhyner, M. N., Ruan, G., 
and Nie S., Physical Chemistry Chemical Physics., 8: 33, 3895-3903 (2006).

7. Wei G. H.,Zhou Z., andLiu Z. Applied Surface Science., 240: (2007).

8. Wang, H.Y.; Li ,Y. F.; Hua, C. Z. Talanta. 2007, 72, 1698-1703.

9. Ahmad N.,Alam, M. K.,Singh V. N.,Sharma S. Journal of Bionanoscience., 3: 97104(2009).

10. Ahmad N.,Sharma S.,Alam M. K.,Singh V. N., Shamsi, S. F.,Mehta B. R.,Fatma A and Colloids and Surfaces B: Biointerfaces.,81: 81-86(2010).

11. Ahmad N., and Ahmad S. S. International Journal of Green Nanotechnology., 3: 109117(2011).

12. Ankamwar B.,Chaudhary M., and Sastry M. Synthesis and Reactivity in Inorganic and Metal-Organic Chemistry.,35: 19-26(2005).

13. Chandran S.P., Chaudhary, M., Pasricha R.,Ahmad A. Sastry M., Bio- technology Progress.,22: 577-583(2006).

14. Dubey S. P.,Lahtinenb M.,Heikki S.,Sillan M. Colloids and Surfaces B: Biointerfaces., 80: 26-33(2010).

15. Zahir A.A., Bagavan A., Kamaraj C., Elango G.,Rahuman A. A. Journal of Biopesticides., 288: 95-102(2012)..

16. Gardea-Torresdey J.L.,Parsons,J.G.,Gomez, E.,PeraltaViddea, J.,Troiani, H. E.,Santiago, P., and Yacaman, M. J. Nano Letters., 2: 397401(2002).

17. Kumar, V., Yadav, S. K. Journal of Chemical Technology and Biotechnology., 84:151157(2009).

18. Shankar S.,Ahmad A., and Sastry M., Biotechnology Progress., 19:16271631(2009).

19. Emeka E.E.,Ojiefoh O.C.,Aleruchi C.,Hassan L.A., Christiana O.M., Rebecca M., Dare E.O., Temitope A.E.Micron,. (2013),

20. Gopi D.,Kanimozhi K.,Bhuvaneshwari N.,Indira J., and Kavitha L. Spectrochim Acta A Mol Biomol Spectrosc., 118:58997(2014).

21. He, Y.,Du, Z.,Lv, H.,Jia, Q.,Tang, Z.,Zheng, X.,Zhang, K.,Zhao, F. Int J Nanomedicine., 8,1809-1815(2013)

22. Arunachalam K.D., and Annamalai SK. Int J Nanomedicine, . 8, 2375-2384(2013).
23. Narayanan KB.,Park HH., and Sakthivel N. Spectrochim Acta A Mol Biomol Spectrosc., 116:485-490(2013).

24. Sulaiman GM.,Mohammed WH.,Marzoog, TR.,Al-Amiery AA.,Kadhum AA.,Mohamad, AB., and Bagnati, R. Asian Pac J Trop Biomed,3:58-63(2013).

25. Annamalai A.,Christina V.L.,Sudha D.,Kalpana M., and Lakshmi P.T. Colloids Surf B Biointerfaces. 1:108,60-65(2013).

26. Ashokkumar, S., Ravi S., and Velmurugan, S. Spectrochim Acta A Mol Biomol Spectrosc., ,115:388-92(2013).

27. Antony, JJ., Nivedheetha, M.,Siva, D.,Pradeepha, G.,Kokilavani, P.,Kalaiselvi, S., Sankarganesh, A.,Balasundaram, A.,Masilamani, V., and Achiraman, S. Colloids Surf B Biointerfaces., 1, 20-24(2013).

28. Prakash P.,Gnanaprakasam P.,Emmanuel R.,Arokiyaraj S., and Saravanan.M. Colloids Surf B Biointerfaces., 1:255-259(2013).

29. Suman TY.,Radhika Rajasree SR.,Ramkumar R.,Rajthilak C., and Perumal, P. Spectrochim Acta A Mol Biomol Spectrosc. 118:1116(2014).

30. Tho N.T., and An T.N., Acta Chim Slov. 60:673-678 (2013). PMID: 24169723 Pub Med - in process

31. Zaheer Z, Rafiuddin., Colloids Surf B Biointerfaces. 1: 90-94(2013).

32. Zayed M.F., and EisaW.H., Spectrochim Acta A Mol Biomol Spectrosc. 3:,238-244(2013).

33. Iravani, S., and Zolfaghari, B. Biomed Res Int., 639725(2013).

34. Seralathan, J., Stevenson, P, Subramaniam, S., Raghavan, R., Pemaiah, B., Sivasubramanian, A., Veerappan A. Spectrochim Acta A Mol Biomol Spectrosc., 118:349-355( 2014).

35. Veerakumar K.,Govindarajan M., and Rajeswary M. Parasitol Res., 112: 40734085( 2013).

36. Rajakumar G.,Rahuman AA.,Jayaseelan C., Santhoshkumar T.,Marimuthu S.,Kamaraj, C.,Bagavan A.,Zahir, AA.,Kirthi, AV.,Elango, G.,Arora, P.,Karthikeyan, R.,Manikandan, S., and Jose S. Parasitol Res., (2013). Epub ahead of printPMID:24265057

37. Ajitha B., Ashok Kumar Reddy Y., and Reddy P.S. Spectrochim Acta A Mol Biomol Spectrosc., 121C:164-172(2013). 
38. Ashokkumar S.,Ravi S.,Kathiravan V., and Velmurugan, S. Spectrochim Acta A Mol Biomol Spectrosc., 121C:88-93(2013).

39. Mahdavi M.,Namvar F.,Ahmad, MB.,Mohamad R. Molecules., 21: 5954-5964(2013).

40. Melegari SP.,Perreault, F.,Costa RH.,Popovic R.,Matias, WG. Aquat Toxicol., 142-143:431440(2013).

41. Qian Y.,Yu H.,He D., Yang H.,Wang W.,Wan X., and Wang L. Bioprocess Biosyst Eng., 36:1613-1619(2013).

42. Quester K.,Avalos-Borja, M.,Vilchis-Nestor A.R.,Camacho-López M.A., and CastroLongoria E. PLoS One., 8:e77486(2013).

43. HeM C.,LiuM L.,FangM Z.,LiM J.,GuoM J., and WeiM J. Ultrason Sonochem., 21:542548(2014).

44. Manikprabhu., M D., and Lingappa. M. K., Bioinorg Chem Appl., 341798(2012).

45. Caddeo, M .C.,Chessa, M .M.,Vassallo, M. A.,Pons M. R.,Diez-SaleM,s O.,Fadda,M .A.M., and Manconi M., J Biomed Nanotechnol. 9:1929-1938(2013).

46. Kuang M.Y.,WangM. Q.,ChenM .Z.,Megharaj M., and Naidu R. J. Colloid Interface Sci., 410:67-73( 2013).

47. Yan,M. J.K.,Cai PF.,Cao, X.Q.,Ma, H.L.,Zhang Q.,Hu, N.Z., and Zhao Y.Z. Carbohydr Polym. 97:391-397.

48. Xia Y.,Xiao Z., Dou X.,Huang H.,Lu X., Yan R.,Gan Y.,Zhu W., Tu J.,Zhang W., and Tao X. ACS Nano., 7:7083-7092(2013).

49. Thenmozhi M.,KannabiranK.,Kumar, R., and Gopiesh Khanna V. J Mycol Med. ,23:97103(2013).

50. Liu B.,Li, X.,Zheng C., and Wang, X. Nanotechnology., 24:235601(2013) .

51. El-Batal Al.,Hashem A.A., and Abdelbaky N.M. Springerplus., 23:129(2013).

52. Hosseini-Abari, A.,Emtiazi, G., and Ghasemi, S.M. World J Microbiol Biotechnol. 29:23592364(2013).

53. Singh S., Vidyarthi AS.,Nigam VK., and Dev A. Artif Cells Nanomed Biotechnol., 26: 273-277 (2013).

54. Zaera F.,Gellman A. J., and Somarjai A. Accounts of Chemical., 19:24-31(1986).

55. Fendler J. H., Chemical Reviews., 87:877-899( 1987).

56. Lewis L. N., Chemical Reviews., 93:2693-
2730(1993).

57. Pal T.,Sau T. K., and Jana N. R., Langmuir., 13:1481-1485(1997).

58. Bakshi M. S.,Possmayer F., and Petersen N. O., Journal of physical chemistry C., 111:14113-14124(2007).

59. Khullar P.,Mahal A.,Singh, V.,Banipal T. S.,Kaur G., and Bakshi M. S.,Langmuir., 26:11363-11371(2010).

60. Ball P.,'When Size Does Matter," Nature., 349: 101(1991).

61. Tian X.,Wang W., and Cao, G., Materials Letters., 61: 130-133(2007).

62. Sarvesh Kumar Srivastava.,Ryosuke Yamada.,Chiaki Ogino., and Akihiko Kondo. Nanoscale Res Lett., 8: 70(2013).

63. Umesh Kumar Parida., Birendra Kumar Bindhani., and Padmalochan Nayak. WJNSE., ,1: (2011)

64. Ramesh Kumar Petla.,Singaravelu Vivekanandhan.,Manjusri Misra.,Amar Kumar Mohanty., and Nallani Satyanarayana. Journal of Biomaterials and Nanobiotechnology., 3: 14-19 (2012).

65. Naheed Ahmad., and Seema Sharma. Green and Sustainable Chemistry.,2:141147(2012)

66. Curwin, B., and BertkeS. J Occup Environ Hyg., 8:580-587(2011).

67. Huayan Yang.,Yu Wang.,Huaqi Huang.,Lars Gell.,Lauri Lehtovaara.,Sami Malola.,Hannu Häkkinen., and Nanfeng Zheng. Nature Communications.,4: (2013),

68. Akl M. Awwad.,Nidá M. Salem, Nanoscience and Nanotechnology., 2: 208-213,

69. Ravindra P, Singh., Vineet K, Shukla., Raghvendra S. Yadav.,Prashant K, Sharma., Prashant K, Singh.,Avinash C, Pandey . Adv. Mat. Lett. 2: 313-317(2011),

70. Foba-Tendo J.Ngenefeme., Namanga J. Eko., Yufanyi D. Mbom.,Ndinteh D. Tantoh., and Krause W. M. Rui. OJCM., 3: (2013),

71. Vinod V.T.,Saravanan P.,Sreedhar B.,Devi D.K.,Sashidhar R.B. Colloids Surf $B$ Biointerfaces. , 83: 291-298(2011).

72. Cheng N ., Tian J.,Liu Q., Ge C.,Qusti A.H.,Asiri A.M.,Al-YoubiA.O., and Sun X. ACS Appl Mater Interfaces. ,5:6815-6819(2013).

73. da Costa J.P., Girão A.V ., Lourenço J.P.,Monteiro O.C., Trindade T., and Costa 
M.C. 128:226-232(2013).

74. Tzeng S.Y., and Green, J.J. Therapeutic nanomedicine for brain cancer. Ther Deliv., 4:687-4704(2013).

75. BarmanG; Maiti S ., and Laha J.K. Nanoscale Res Lett., 8:181(2013).

76. Xia B.,He F., and Li L. Langmuir. ,29:49014907(2013).

77. Ramamurthy C.H.,Sampath K.S.,Arunkumar P.,Kumar M.S.,Sujatha V., and Premkumar K.,Thirunavukkarasu C. Bioprocess Biosyst Eng., 36:1131-9(2013).

78. Ganeshkumar M.,Sathishkumar M.,Ponrasu T.,Dinesh MG., and Suguna L.Colloids Surf $B$ Biointerfaces., 106:208-16.

79. WuY, ., Yang D., Kang X., Ma, P.,Huang S., Zhang Y., Li. C., and Lin J.Dalton Trans., 42:9852-61(2013).

80. Malathi S., and Balasubramanian,S.J.Biomed. Nanotechnol., 7: (2011),

81. Paleos C. M.,Tsiourvas D.,Sideratou Z., Tziveleka L. Biomacromolecules, 5: 524(2004).

82. Kisak E. T.,Coldren B.,Evans C. A.,Boyer C., and Zasadzinski J. A. Curr.Med.Chem. 11: 199(2004).

83. WuW.,Wieckowski G.,Pastorin M.,Benicasa M.,Klumpp C.,Briand J. P.,Genaro, R.,Prato M., and Bianco A. Angew.Chem,Int.Ed., 44: 6358(2005).

84. Salem A. K.,Searson P. C., and Leong K. W. Nature Mater., 2: 668(2003).

85. Reddy NJ., Nagoor Vali D.,Rani M., and Rani SS. Mater Sci Eng C Mater Biol Appl., 1:11522(2014).

86. Yoon H.K.,Ray, A., Lee Y.E.,Kim G., Wang X., and Kopelman R.J. Mater Chem B Mater Biol Med., 1: (2013).

87. Balachandran Y.L.,Girija S., and Selvakumar R., Tongpim S., Gutleb A.C., Suriyanarayanan,
S.PLoS One. ,8 :e77043(2013).

88. Shiny PJ., Mukherjee A., and Chandrasekaran N.Bioprocess Biosyst Eng., Oct 6. Epub ahead of print (2013).

89. Arunachalam K.D., Annamalai S.K.Int J Nanomedicine., 8:2375-2384(2013).

90. Li Y., Ma J.,Zhu H., Gao X., Dong H., and Shi D.ACS Appl Mater Interfaces., 5:72277235(2013).

91. Karuppaiya P.,Satheeshkumar E.,Chao W.T., Kao L.Y., Chen E.C., and Tsay H.S.Colloids Surf B Biointerfaces., 110:163-170(2013).

92. Rubilar O., Rai M., Tortella. G.,Diez M.C., Seabra A.B., Durán, N.Biotechnol Lett., 35:1365-1375(2013).

93. Cai H, Yao P.Nanoscale., 5: 28922900(2013).

94. Filser J., Arndt D., BaumannJ., Geppert M., HackmannS., Luther E.M., Pade, C., Prenzel,K., Wigger, H.,Arning, J., Hohnholt M.C., Köser J., Kück A., Lesnikov E., Neumann J, Schütrumpf, S, Warrelmann, J, Bäumer, M, Dringen, R, von Gleich, A., Swiderek P., and Thöming, J.Nanoscale., 5:1034-1046(2013).

95. Verma ML.,Barrow C.J., and Puri M.Appl Microbiol Biotechnol. 97: 23-39(2013).

96. Mukherjee S., Sushma V., Patra S., Barui AK., Bhadra MP., Sreedhar B., and Patra C.R.Nanotechnology. ,23: 455103(2012).

97. Kashyap, PL.,Kumar, S.,Srivastava, A.K., and Sharma, A.K.World J Microbiol Biotechnol., 29: 191-207 (2013).

98. Pandey S.,Goswami G.K., and Nanda K.K.Int J Biol Macromol., 5:583-9(2012).

99. Vidhu VK.,Philip. D.Micron. ,56:54-62(2014). 100. Jeon E.K., Seo E., Lee E., Lee, W., Um M.K., and Kim B.S.Chem Commun (Camb)., 49,3392-3394 (2013). 